\title{
Distending pressure in infants with respiratory distress syndrome
}

\author{
J. D. BAUM and N. R. C. ROBERTON \\ From the Department of Paediatrics, University of Oxford, John Radcliffe Hospital, Oxford
}

Baum, J. D., and Roberton, N. R. C. (1974). Archives of Disease in Childhood, 49, 771. Distending pressure in infants with respiratory distress syndrome. The application of distending pressure to 40 babies with the respiratory distress syndrome (RDS) is described. Pressures greater than $10 \mathrm{~cm} \mathrm{H}_{2} \mathrm{O}$ were rarely used. On starting distending pressure, considerable improvements in blood gases occurred in all but 4 babies, 2 of whom had pneumothoraces and the other rapidly deteriorated and died from an intraventricular haemorrhage shortly afterwards.

In 27 babies the distending pressure was applied for hypoxaemia during the course of the disease. 16 survived without further intervention, though one case eventually required long-term continuous distending pressure (CDP) for pulmonary oedema. 11 out of the 27 required intermittent positive pressure ventilation (IPPV), with 6 survivors.

In 13 other babies who had not received CDP previously, the technique was used to assist weaning from IPPV. It sustained oxygenation in each case, and 12 of these babies survived.

Seven babies developed pneumothoraces and 2 babies intrapulmonary cysts. 6 babies died, 3 with pneumothoraces. The overall incidence of intraventricular haemorrhage was 3 proven and 2 suspected cases. There was no evidence that distending pressure in any form increased the incidence of intracranial haemorrhage.

The various techniques for administering continuous positive airways pressure (CPAP) and continuous negative pressure have been usefully grouped together by Chernick (1973) under the term continuous distending pressure (CDP). CDP has been shown to give significantly better results than conventional therapy in the management of infants with respiratory distress syndrome due to hyaline membrane distress (Fanaroff et al., 1973; Rhodes and Hall, 1973). In addition, CDP has proved useful in weaning infants off ventilators (Cumarasamy et al., 1973) and in situations where pulmonary oedema proves difficult to control in infants breathing spontaneously (Hatch et al., 1973; Roberton, 1974).

We describe our experiences over a 20-month period with the use of CDP administered to 40 babies, of whom 34 survived.

\section{Materials and methods}

All babies were on the Special Care Baby Unit of our hospital. 36 were born in the hospital and 4 were

Received 15 March 1974. referred from outside centres. All babies were suffering from RDS according to the standard criteria (Davies $e t$ al., 1972). They were nursed naked in a thermal environment to keep their abdominal skin temperature in the range of $36-36 \cdot 5{ }^{\circ} \mathrm{C}$.

Umbilical arterial and venous catheters were inserted in all cases as soon as the diagnosis was made. The arterial catheter was used for blood pressure monitoring as well as blood sampling, and was left in situ for as long as required. Sufficient oxygen was given to keep the arterial $\mathrm{PO}_{2}$ in the range of $60-90$ torr, and base was given to correct $p \mathrm{H}$ to $7 \cdot 25$. When possible, hourly tube feeds of expressed breast milk were given. When CDP was administered by head box or when feeds accumulated in the stomach, $10 \%$ dextrose with appropriate electrolyte supplements was given through one of the umbilical catheters.

Blood gases were measured on an IL 313 Blood Gas analyser. In most infants early assessment of severity was carried out using the hyperoxia test (nitrogen washout test). The inability to achieve an arterial $\mathrm{Po}_{2}$ of $>-100$ torr while breathing pure oxygen, within the first 6 hours, used to carry a poor prognosis (Boston, Geller, and Smith, 1966; Roberton et al., 1968). To allow comparisons between arterial oxygen tensions at different alveolar oxygen concentrations the alveolar-arterial 
oxygen difference $\left(\mathrm{A}-\mathrm{aDO}_{2}\right)$ was calculated, using the alveolar air equation and assuming a respiratory quotient of $\mathbf{0 \cdot 8}$.

$$
\mathrm{PAO}_{2}=\mathrm{FIO}_{2}-\mathrm{PACO}_{2}\left[\mathrm{FrO}_{2}+\frac{1-\mathrm{FrO}_{2}}{\mathrm{R}}\right]
$$

where $\mathrm{PAO}_{2}$ is alveolar oxygen tension; $\mathrm{FIO}_{2}$ is inspired oxygen concentration; $\mathrm{PACO}_{2}$ is alveolar $\mathrm{CO}_{2}$ tension assumed to be the same as arterial $\mathrm{CO}_{2}$ tension; $\mathrm{R}$ is respiratory quotient. Thus a decrease in $\mathrm{A}-\mathrm{aDO}_{2}$ represents improving pulmonary function and oxygenation and vice versa.

CDP was applied in three ways. (1) CPAP was applied by means of a head box. The system originally described by Gregory et al. (1971) was used; initially using a home-made box and more recently a Vickers head box. (2) Alternatively, CPAP was applied by means of an endotracheal tube; Etches, Houghton, and Moore (1973) have described our technique of administering CPAP using the Bennett PR2 special ventilator with the rate control turned down to zero. (3) Continuous negative pressure was applied using the Pulmarca 1400 chamber (Draeger Ltd). Whichever technique of CDP was applied, the pressure rarely exceeded $10 \mathrm{~cm} \mathrm{H}_{2} \mathrm{O}$.

Indications for CDP. We have three indications for starting distending pressure during the evolution of RDS. (1) When the infant is unable to maintain an arterial $\mathrm{Po}_{2}$ of $>60$ torr in $\mathrm{FIO}_{2} 0.6$ or greater. (2) In the presence of less severe blood gas abnormalities when the infant is 'working hard' as assessed clinically, and if the signs are present early, the infant is of very low birthweight, and radiological changes are severe. (3) In attempting to wean from intermittent positive pressure ventilation (IPPV) when the infant is unable to sustain an adequate $\mathrm{PaO}_{2}$ breathing spontaneously at atmospheric pressure.

\section{Results}

The clinical details of the infants studied are shown in Tables I to IV. 16 babies required CDP only. All of these survived (Table I). 11 babies started with CDP but their condition subsequently deteriorated and IPPV was required. 5 of these died, and 6 survived (Table II), CDP having been used to wean them off IPPV. A further 12 babies, who had started IPPV without previous CDP improved sufficiently for them to sustain adequate gas exchange when CDP was substituted for the IPPV. All but one of these survived (Table III). 2 further cases required very long-term CDP for the control of pulmonary oedema associated with a persistent ductus arteriosus (Table IV). One of these (Case 11) had already been treated in the head box. Several babies received distending pressure by more than one technique (Table V).

Thirty-two of the babies had hyperoxia tests before 6 hours of age. 18 were in the 'good prognosis' range; 15 of these survived. 14 were in the 'bad prognosis' range; 12 of these survived. 8 in this latter group required assisted ventilation within 6 hours of birth, and of the other 6,4 required only CDP and the other 2 died on IPPV. Of the 15




'good prognosis' survivors, 7 required periods of IPPV in addition to CDP.

Effects on oxygenation (Fig. 1-3). We have blood gas data covering the period when distending pressure was begun on 31 occasions in 28 babies (Fig. 1). On 27 occasions the $\mathrm{A}-\mathrm{aDO}_{2}$ decreased, indicating improved oxygenation. Of the 4 cases in whom the $\mathrm{A}-\mathrm{aDO}_{2}$ deteriorated on starting distending pressure, 2 (Cases 20,24) had pneumothoraces, the third (Case 27) was deteriorating rapidly and died shortly afterwards, but the fourth (Case 9, Table VI) made satisfactory progress. There was no apparent correlation between the degree of improvement in oxygenation (assessed by a decreasing $\mathrm{A}-\mathrm{aDO}_{2}$ ) and the length of time distending pressure was necessary, nor the need for subsequent positive pressure ventilation.

CDP was reduced gradually in all cases. Despite this precaution in the 33 cases where blood gas analyses were taken just before and just after discontinuing distending pressure, the $\mathrm{A}-\mathrm{aDO}_{2}$ increased in all but 4 cases (Fig. 2). This indicated persisting pulmonary disease but also showed the effectiveness of even very low pressure $(1 \cdot 5-2 \mathrm{~cm}$ $\mathrm{H}_{2} \mathrm{O}$ ) in improving arterial oxygenation. In general, the greater the rise in the $\mathrm{A}-\mathrm{aDo}_{2}$ on discontinuing distending pressure, the greater the likelihood of further ventilatory assistance being required. Babies whose $\mathrm{A}-\mathrm{aDO}_{2}$ did not increase to more than 240 torr were unlikely to deteriorate again

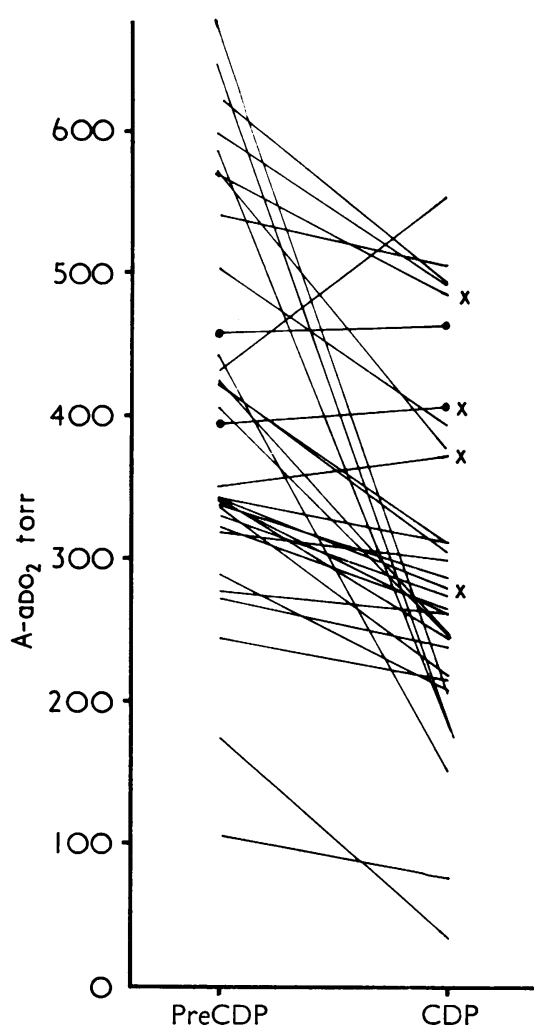

Fig. 1.-A-aDO ${ }_{2}$ before and after starting CDP. A fall in $A-a_{2} O_{2}$ means improving oxygenation. $\times$, died; , pneumothorax when CDP started.

I

pressure only. All survived

\begin{tabular}{|c|c|c|c|c|}
\hline \multirow{2}{*}{$\begin{array}{l}\text { Age (hr) distending } \\
\text { started }\end{array}$} & \multirow{2}{*}{$\begin{array}{l}\text { Duration (hr) of } \\
\text { distending pressure }\end{array}$} & \multicolumn{2}{|c|}{ Duration of exposure to $\mathrm{FiO}_{2}>0.6$} & \multirow{2}{*}{ Complications } \\
\hline & & $\begin{array}{l}\text { In distending } \\
\text { pressure (hr) }\end{array}$ & $\begin{array}{c}\text { Total } \\
(\mathrm{CDP}+\text { spontaneous })\end{array}$ & \\
\hline $\begin{array}{l}10 \\
13\end{array}$ & $\begin{array}{l}82 \\
65\end{array}$ & $\begin{array}{r}2 \\
11\end{array}$ & $\begin{array}{r}2 \\
11\end{array}$ & $\begin{array}{l}1 \mathrm{ETT} \text { change; } \overline{\text { Esch. }} \text { coli in ETT } \\
\text { aspirate }\end{array}$ \\
\hline $\begin{array}{l}38 \\
34\end{array}$ & 17 & 0 & 17 & 二 \\
\hline $\begin{array}{l}34 \\
11\end{array}$ & $\begin{array}{l}24 \\
58\end{array}$ & $\begin{array}{l}1 \\
0\end{array}$ & $\begin{array}{r}31 \\
3\end{array}$ & Pulmonary cysts \\
\hline 6 & 60 & 3 & 8 & \\
\hline 8 & 35 & 0 & 16 & Esch. coli in blood culture \\
\hline 8 & 65 & 3 & 11 & - \\
\hline 31 & 61 & 25 & 41 & 一 \\
\hline 10 & 33 & 0 & 4 & $\begin{array}{l}\text { Anal atresia; transferred for surgery } \\
45 \mathrm{hr}\end{array}$ \\
\hline 5 & 31 & 0 & 3 & See Table IV and text \\
\hline 28 & 44 & 19 & 94 & Pneumothorax \\
\hline $\begin{array}{l}9 \\
3\end{array}$ & $\begin{array}{l}16 \\
28\end{array}$ & $\begin{array}{l}0 \\
2\end{array}$ & $\begin{array}{l}2 \\
5\end{array}$ & $\overline{-}$ \\
\hline 58 & 64 & 21 & 77 & 1 ETT change; Esch. coli in ETT \\
\hline 36 & 48 & 6 & 10 & aspirate \\
\hline
\end{tabular}


Babies starting on distending pressure ând



HMD, hyaline membrane disease; BPD, bronchopulmonary dysplasia; IVH, intraventricular haemorrhage.

TABNE

Infants starting with IPPV and who weje

\begin{tabular}{|c|c|c|c|c|c|c|c|}
\hline Case no. & Sex & $\begin{array}{c}\text { Birthweight } \\
\text { (g) }\end{array}$ & $\begin{array}{l}\text { Gestational } \\
\text { age (wk) }\end{array}$ & $\begin{array}{l}\text { Type of } \\
\text { distending } \\
\text { pressure }\end{array}$ & $\begin{array}{l}\text { Pressure used } \\
\quad\left(\mathrm{cmH}_{2} \mathrm{O}\right)\end{array}$ & $\begin{array}{l}\text { Age }(\mathrm{hr}) \\
\text { distending } \\
\text { pressure } \\
\text { applied }\end{array}$ & Disten \\
\hline $\begin{array}{l}28 \\
29\end{array}$ & $\begin{array}{c}\mathbf{M} \\
\mathbf{F}\end{array}$ & $\begin{array}{l}1200 \\
1790\end{array}$ & $\begin{array}{l}30 \\
30\end{array}$ & $\begin{array}{l}\text { ETT } \\
\text { ETT, Box }\end{array}$ & $\begin{array}{l}5-8 \\
4-10\end{array}$ & $\begin{array}{r}3 \\
63\end{array}$ & $\begin{array}{l}63 \\
85\end{array}$ \\
\hline $\begin{array}{l}30 \\
31 \\
32\end{array}$ & $\begin{array}{l}\mathbf{F} \\
\mathbf{F} \\
\mathrm{F}\end{array}$ & $\begin{array}{l}3440 \\
1670 \\
2270\end{array}$ & $\begin{array}{l}42 \\
33 \\
34\end{array}$ & $\begin{array}{l}\text { ETT } \\
\text { ETT, Box } \\
\text { ETT, Box }\end{array}$ & $\begin{array}{l}3-5 \\
4-13 \\
3-8\end{array}$ & $\begin{array}{l}5 \frac{1}{2} \\
41 \\
28\end{array}$ & $\begin{array}{r}7 \\
26 \\
107\end{array}$ \\
\hline $\begin{array}{l}33 \\
34 \\
35\end{array}$ & $\begin{array}{l}\mathbf{F} \\
\mathbf{F} \\
\mathbf{F}\end{array}$ & $\begin{array}{l}3870 \\
2660 \\
1290\end{array}$ & $\begin{array}{l}37 \frac{1}{2} \\
37 \\
28\end{array}$ & $\begin{array}{l}\text { ETT } \\
\text { Bcx } \\
\text { ETT }\end{array}$ & $\begin{array}{c}7-8 \\
? \\
3-10\end{array}$ & $\begin{array}{c}15 \frac{1}{2} \\
26 \\
2 \frac{1}{2}\end{array}$ & $\begin{array}{l}60 \\
66 \\
99\end{array}$ \\
\hline $\begin{array}{l}36 \\
37\end{array}$ & $\begin{array}{l}\mathrm{F} \\
\mathrm{F}\end{array}$ & $\begin{array}{l}1430 \\
2730\end{array}$ & $\begin{array}{l}29 \\
40\end{array}$ & $\begin{array}{l}\text { ETT } \\
\text { ETT }\end{array}$ & $\begin{array}{l}7 \\
2-7\end{array}$ & $\begin{array}{l}10 \\
17\end{array}$ & $\begin{array}{l}66 \\
95\end{array}$ \\
\hline $\begin{array}{l}38 \\
39\end{array}$ & $\begin{array}{l}\mathrm{F} \\
\mathbf{M}\end{array}$ & $\begin{array}{l}3510 \\
1860\end{array}$ & $\begin{array}{l}39 \\
39\end{array}$ & $\begin{array}{l}\text { ETT } \\
\text { ETT }\end{array}$ & $\begin{array}{l}4-7 \\
4-7\end{array}$ & $\begin{array}{r}55 \\
2\end{array}$ & $\begin{array}{l}39 \\
35\end{array}$ \\
\hline
\end{tabular}

TABEF

Babies requiring long-term distendikg

\begin{tabular}{|c|c|c|c|c|c|c|c|}
\hline \multirow{2}{*}{ Case no. } & \multirow[b]{2}{*}{ Sex } & \multirow{2}{*}{$\begin{array}{l}\text { Birthweight } \\
\text { (g) }\end{array}$} & \multirow{2}{*}{$\begin{array}{l}\text { Gestational } \\
\text { age (wk) }\end{array}$} & \multirow{2}{*}{$\begin{array}{l}\text { Pressure used } \\
\text { (both ETT) }\end{array}$} & \multirow{2}{*}{$\begin{array}{c}\text { Age started } \\
(\mathrm{hr})\end{array}$} & \multicolumn{2}{|c|}{ Distending pressure } \\
\hline & & & & & & $\begin{array}{l}\text { Duration } \\
(\mathrm{hr})\end{array}$ & 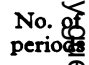 \\
\hline 40 & $\mathbf{F}$ & 1190 & 28 & $2-10$ & 21 & 746 & $10 \stackrel{\omega}{+}$ \\
\hline 11 & $\mathbf{M}$ & 1650 & 29 & $4-7$ & 170 & 292 & $5 \frac{\mathrm{T}}{\mathrm{O}}$ \\
\hline
\end{tabular}


TABLE V

Routes by which CDP was administered to 40 babies

\begin{tabular}{lr}
\hline ETT only & 17 \\
Head box only & 14 \\
Negative pressure (CNP) only & 2 \\
Head box \& ETT & 6 \\
Head Box \& CNP \& ETT & 1 \\
\hline
\end{tabular}

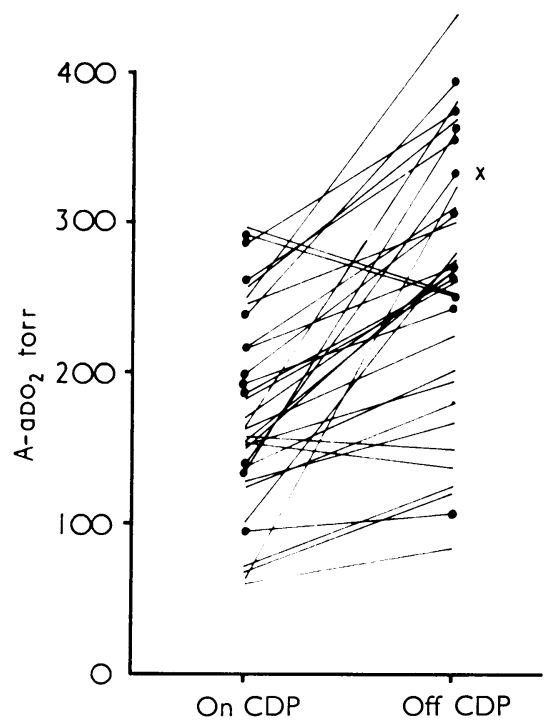

FIG. 2.- $A-a D O_{2}$ when $C D P$ was discontinued. $A$ rise in $A-a \mathrm{DO}_{2}$ means deteriorating oxygenation. $\times$, died; - required subsequent ventilatory assistance.

(Fig. 2). There did not seem to be a greater likelihood of deterioration after stopping CDP if it had been administered by head box or tube, particularly when allowance is made for the fact that babies receiving CDP by tube had often been ventilated previously.

In 26 cases blood gases were analysed before and after converting from IPPV to CDP. There was a marked improvement in $\mathrm{A}-\mathrm{aDO}_{2}$ in 13 cases (Fig. 3) and in 13 cases it deteriorated. Improvement was most often found in those babies who had been very active and restless while ventilated, yet were unable to sustain an adequate $\mathrm{PaO}_{2}$ when breathing spontaneously in high oxygen concentrations at atmospheric pressure. There was no association between change in $\mathrm{A}-\mathrm{aDO}_{2}$ and the need for subsequent IPPV.

$\mathbf{P C O}_{2}$ changes. We did not set any limit of $\mathrm{PaCO}_{2}$ above which CDP would not be attempted. 9

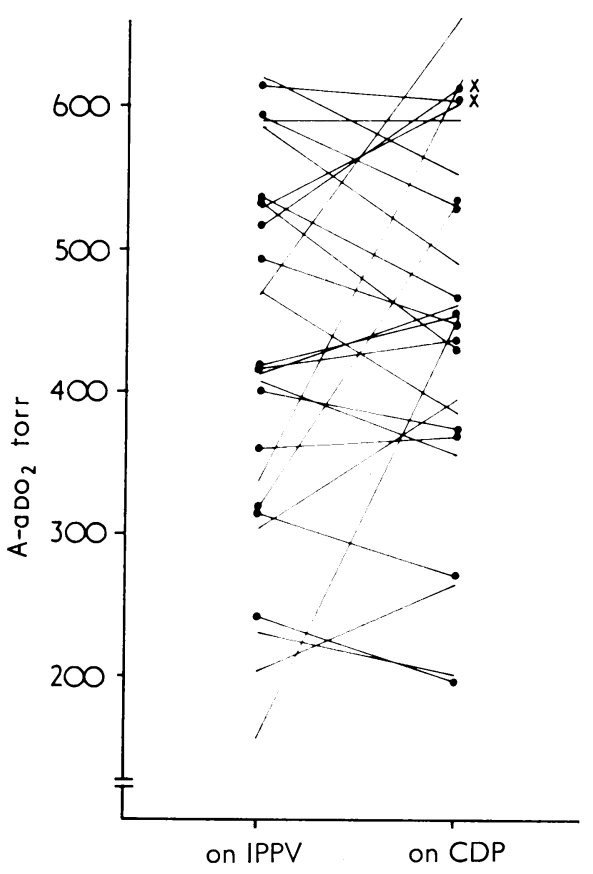

FIg. 3.-Change in $A-a D O_{2}$ when $C D P$ was substituted for IPPV. ๑, IPPV subsequently; $\times$, died.

babies had $\mathrm{PaCO}_{2}>60$ torr on starting CDP and 7 of these survived without additional IPPV. The $\mathrm{PaCO}_{2}$ increased on starting CDP in 11 babies, decreased in 16, and in 3 it remained constant. The most dramatic was a fall from $\mathrm{PaCO}_{2} 115$ to $\mathrm{PaCO}_{2} 60$ in Case 9. A rise in $\mathrm{PaCO}_{2}$ of more than 10 torr occurred in 4 cases when CDP was started. Two subsequently needed IPPV. On stopping distending pressure, $\mathrm{PaCO}_{2}$ increased in 17, fell in 9, and remained constant in 7 . The degree or direction of change bore no relation to the severity of previous illness nor to the need for further distending pressure or IPPV. When distending pressure replaced IPPV, there was a rise in $\mathrm{PaCO}_{2}$ in 16 infants, a fall in 8, and in 2 it remained constant. Of the 8 cases where the $\mathrm{PaCO}_{2}$ fell when distending pressure replaced IPPV, only 2 infants needed subsequent ventilation, compared with 10 out of the 16 who had a rise in $\mathrm{PaCO}_{2}\left(\chi_{2}=1 \cdot 7\right.$, not significant).

Duration of oxygen therapy. In Table $I$ it can be seen that those babies who required CDP alone only had transient subsequent exposure to greater than $60 \%$ oxygen. Even the babies who required periods of positive pressure ventilation 
(Table II) had relatively short exposures to high inspired oxygen tensions, rarely exceeding 100 hours. The 2 infants who died after 64 and 116 hours exposure, however, did have mild histological changes of pulmonary oxygen toxicity at necropsy examination. Babies who started on positive pressure ventilation had longer overall exposure to $\mathrm{FIO}_{2}>0.6$ (Table III) and also longer exposure to distending pressure. Only one of these latter infants died and none of the survivors had signs of persisting chronic lung disease at the time of discharge.

Complications. 7 out of the 40 babies developed pneumothoraces. 2 (Cases 34 and 36) had been ventilated previously but developed the pneumothorax while receiving CDP. Case 24 probably developed his pneumothorax before distending pressure was applied. 5 babies developed pneumothoraces while receiving distending pressure in the head box; one baby was in the negative pressure box, and one was receiving distending pressure through an endotracheal tube.
6 out of the 7 pneumothoraces were drained. 3 babies died (Cases 24, 25, and 26) and in all cases the pneumothorax was considered to be an important factor in the cause of death.

Two babies developed cystic changes in the lung fields. In Case 32 the cyst steadily increased in size (Fig. 4) and was eventually removed. Histology suggested congenital lymphatic cystic disease. Case 5 developed midzone cysts on the fourth day which spontaneously cleared (Fig. 5).

Thirty-one endotracheal tube changes were required in the 22 babies in whom CDP was administered by this route (excluding the 2 infants (Table IV) receiving long-term CPAP). Where the tube was used to administer distending pressure an average of one tube change was required for every 40 hours distending pressure. In most cases the tube had to be changed as an emergency due to obstruction or dislodgement. In these 22 babies, 9 significant cultures (Esch. coli 6, Staphylococcus albus 2 , and Pseudomonas aeruginosa 1) were obtained from tracheal aspirates or on culturing the tip of the endotracheal tube. All 9 babies were treated with

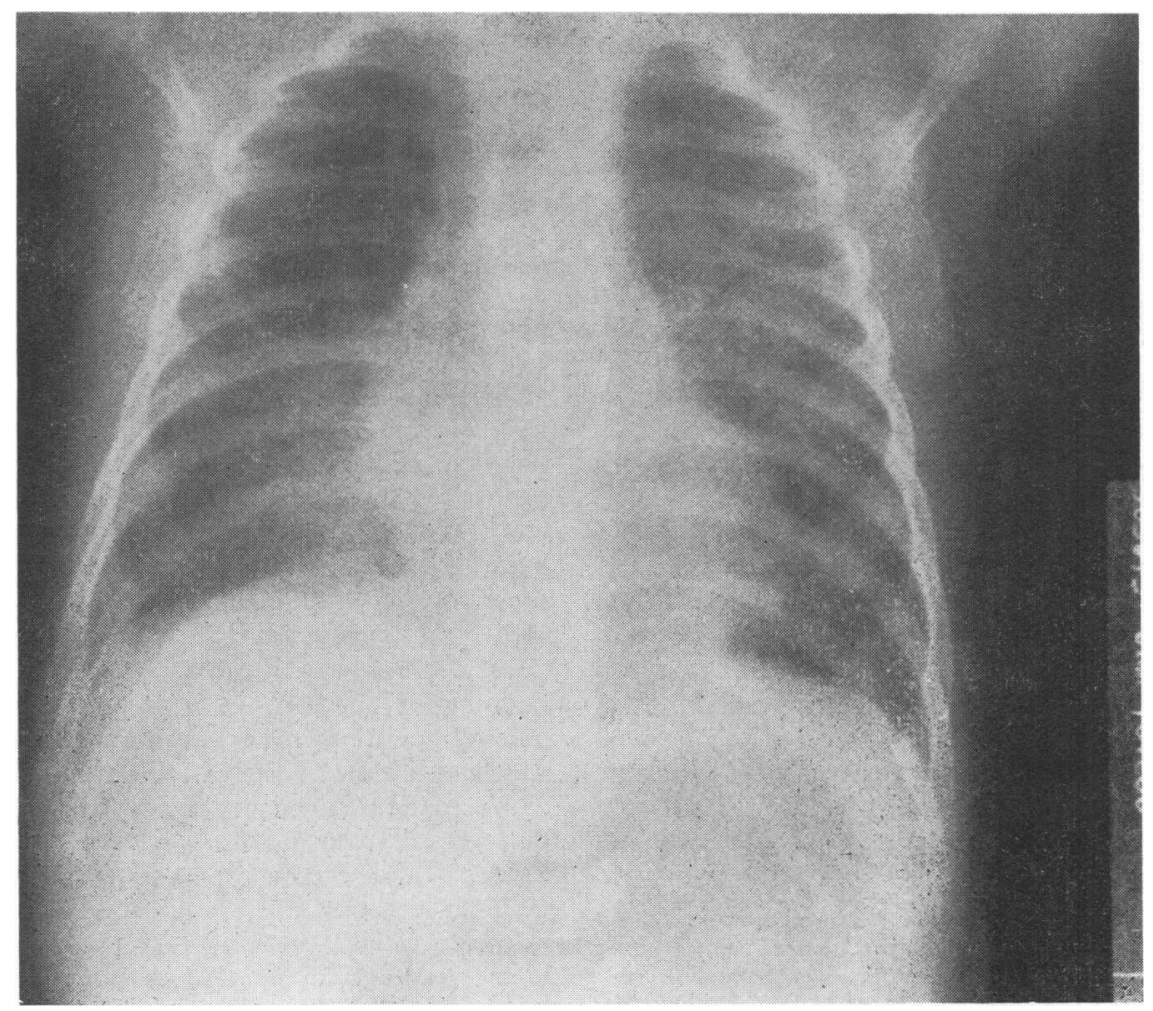

FIG. 4.-Right apical cysts in Case 32, aged 2 months. 


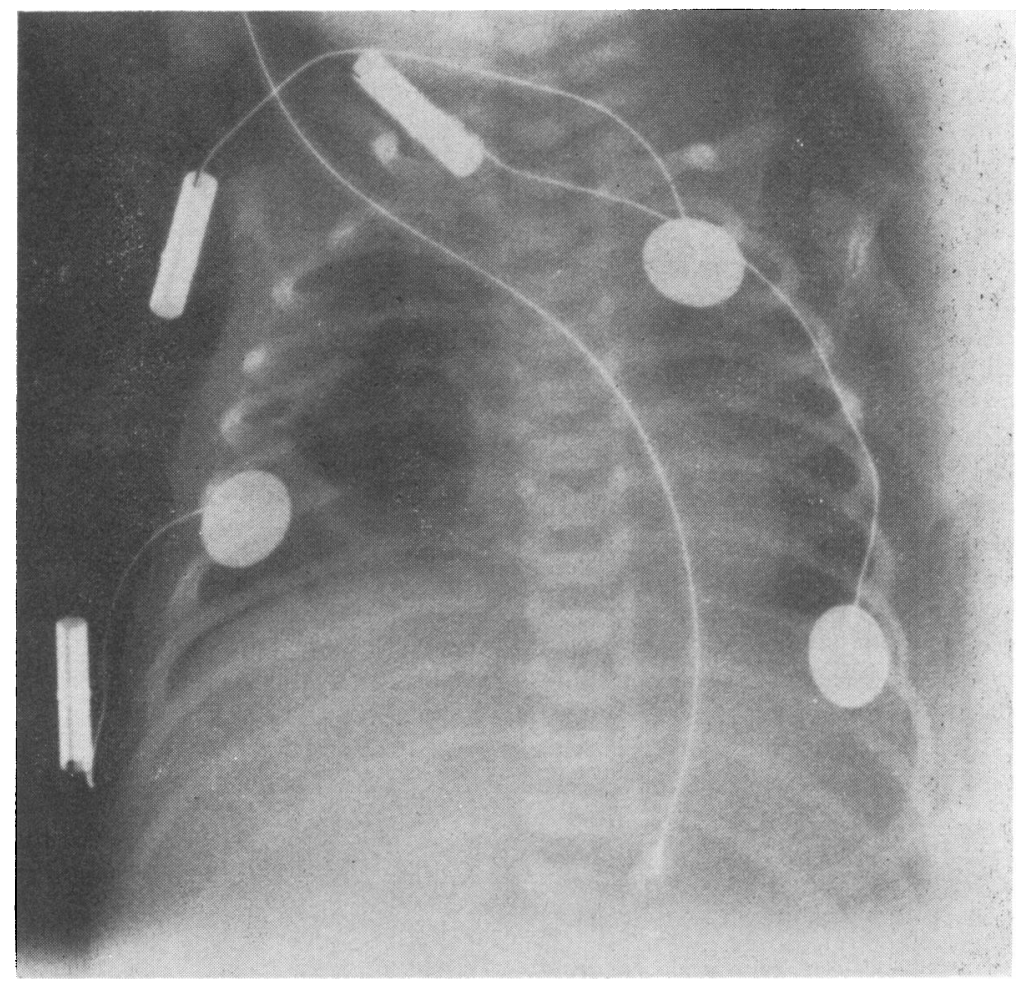

FIG. 5.-Right midzone cysts in Case 5, aged 6 days.

broad spectrum antibiotics and none of them died. Infection was not thought to be an important factor in the 6 deaths in the series.

Cause of death. 6 babies died. In 3 the pneumothorax played a major role in the final deterioration (Cases 24, 25, 26). In Case 24 this was the only post-mortem finding in addition to hyaline membrane disease and early pulmonary oxygen toxicity. Cases 25 and 26 with pneumothoraces were twins who had severe respiratory distress and in whom necropsy was refused, but clinical signs suggested that they had also developed intraventricular haemorrhages. The other 3 infants who died had severe RDS (Cases 23, 27, 39). At necropsy all 3 had classical hyaline membrane disease and 2 (Cases 27,39) had an associated intraventricular haemorrhage: Case 23 also showed early histological changes of pulmonary oxygen toxicity.

\section{Discussion}

Our results confirm the previous satisfactory reports on the use of distending pressure both in terms of improved oxygenation and decreased mortality rate (Gregory et al., 1971; Chernick and Vidyasagar, 1972; Fanaroff et al., 1973; Rhodes and Hall, 1973; Chernick, 1973). The overall mortality rate in this group of $\mathbf{4 0}$ severe cases of RDS was $15 \%$. In only 4 out of the 31 occasions where data are available when distending pressure was applied did the $\mathrm{A}-\mathrm{aDO}_{2}$ fail to improve. 2 of these already had pneumothoraces and the third was rapidly deteriorating and died shortly afterwards while receiving IPPV. The values for the fourth case are shown in Table VI. The $\mathrm{PaO}_{2}$ improved when CDP was applied, but because of the big fall in the $\mathrm{PaCO}_{2}$ plus the rise in $\mathrm{FiO}_{2}$ the $\mathrm{A}-\mathrm{aDO}_{2}$ actually increased. The infant continued to improve and survived without positive pressure ventilation.

We made an arbitrary decision to start CDP at a $\mathrm{PaO}_{2}$ of 60 torr in $\mathrm{FIO}_{2}>0 \cdot 6$. Others (Dunn, Speidel, and Storrs, 1973) recommend applying $\mathrm{CDP}$ at a lower $\mathrm{FIO}_{2}$ requirement. Our practice has been to start with a pressure of $8-10 \mathrm{~cm} \mathrm{H}_{2} \mathrm{O}$. Usually this achieves adequate oxygenation. We have only used pressures in excess of $10 \mathrm{~cm} \mathrm{H}_{2} \mathrm{O}$ on 7 occasions in attempts to improve oxygenation, the 
TABLE VI

Blood gas changes after starting distending pressure in Case 9

\begin{tabular}{l|r|r|r|r}
\hline \multicolumn{1}{c|}{ Age (hr) } & 30 & $31 \frac{1}{2}$ & $34 \frac{1}{2}$ & $38 \frac{1}{2}$ \\
\hline $\mathrm{FrO}_{2}$ & 0.8 & 0.95 & 0.92 & 0.90 \\
$\mathrm{PaO}_{2}$ & 24 & 62 & 50 & 150 \\
${\mathrm{~A}-\mathrm{aDO}_{2}}_{\mathrm{PaCO}_{2}}$ & 447 & 614 & 573 & 552 \\
Distending pressure & 115 & 60 & 78 & 85 \\
$\left(\mathrm{~cm} \mathrm{H}_{2} \mathrm{O}\right)$ & - & 12 & 12 & 12 \\
\hline
\end{tabular}

maximum pressure used being $15 \mathrm{~cm} \mathrm{H}_{2} \mathrm{O}$. In all cases the increase to $>10 \mathrm{~cm} \mathrm{H}_{2} \mathrm{O}$ was successful and it is worth noting that 5 of the babies treated were large (weight $2.30 \mathrm{~kg}$, Case $2 ; 2.97 \mathrm{~kg}$, Case 9; $2 \cdot 77 \mathrm{~kg}$, Case $16 ; 2 \cdot 75 \mathrm{~kg}$, Case 17 ; and $3 \cdot 20 \mathrm{~kg}$, Case 18).

Having established the infant on distending pressure our first priority is to lower the $\mathrm{FiO}_{2}$ to $<0.6$ because of the possible risk of pulmonary oxygen toxicity, and then gradually to lower the pressure to 1-2 $\mathrm{cm} \mathrm{H}_{2} \mathrm{O}$ when, if the baby maintains an adequate $\mathrm{PaO}_{2}$, distending pressure is discontinued. At pressures of $8-10 \mathrm{~cm} \mathrm{H}_{2} \mathrm{O}$ or above, apnoeic attacks occasionally occurred, particularly in babies of less than $1500 \mathrm{~g}$ who were recovering from their respiratory distress. In infants having apnoeic attacks or accumulating $\mathrm{CO}_{2}$ with an adequate $\mathrm{PaO}_{2}$ we found that lowering the pressure usually abolished the attacks and brought down the $\mathrm{CO}_{2}$. The deleterious effects of distending pressure administered to a baby with stable lungs is shown in Fig. 6. This was a premature infant (weight $2030 \mathrm{~g}$, 33 weeks' gestation) who had respiratory difficulties requiring an $\mathrm{FiO}_{2}$ of 0.9 or greater. However, the chest $x$-ray looked normal, and a shake test on the mother's liquor had been positive and the illness was subsequently attributed to a haemophilus influenza pneumonia. Application of CDP caused $\mathrm{CO}_{2}$ accumulation and a marked reduction in the respiratory excursions.

Although our practice has been gradually to reduce distending pressures to $1-2 \mathrm{~cm} \mathrm{H}_{2} \mathrm{O}$, we found (Fig. 2) that most infants increase their $\mathrm{A}-\mathrm{aDO}_{2}$ markedly, even when this low distending pressure is discontinued. Those infants who had the largest rise in $\mathrm{A}-\mathrm{aDO}_{2}$ were those who subsequently needed further CDP or ventilation-(Fig. 2). Large rises in $\mathrm{A}-\mathrm{aDO}_{2}$ also occurred in those babies who had received distending pressure by endotracheal tube and in whom the endotracheal tube was left in situ. It seemed possible that their greater rise in $\mathrm{A}-\mathrm{aDO}_{2}$ was due to inability to grunt; however, all but one of these babies had received IPPV and prolonged oxygen therapy, and though the inability to grunt (Harrison, Heese, and Klein, 1968) may have played a part in increasing their $\mathrm{A}-\mathrm{aDO}_{2}$, the severity of their preceding lung disease
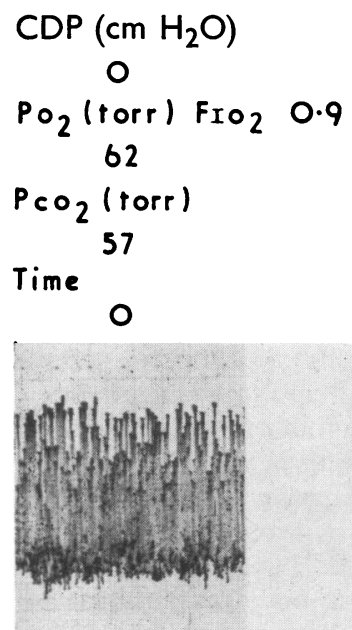

7

55

64

$+16$

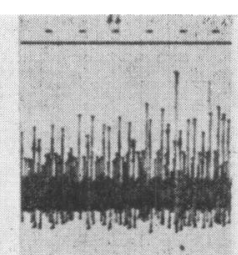

11

50

82
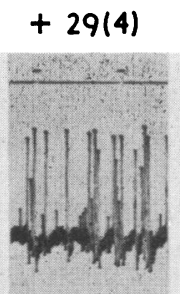

5

66

70

67
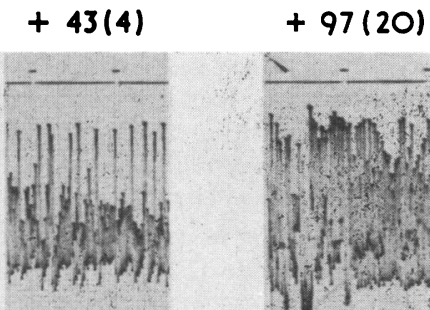

FIG. 6.-Changes in respiratory excursion when CDP was applied to an infant with lungs of presumed normal compliance. (Respirations monitored with an impedance pneumograph). Time refers to minutes after the introduction of CDP at time 0. Figures in parentheses indicate the duration of CDP at the pressure shown when the respiratory record was taken. 
seems a more likely cause. Moreover, we have found it more satisfactory on reducing pressure to zero to leave the tube in situ initially, in case there is rapid deterioration, rather than to remove pressure and tube simultaneously.

One major application of distending pressure which has received comparatively little attention is its use in weaning babies off ventilators. This was used in 21 infants - all the cases shown in Tables III and IV and Cases 17-23 in Table II. Although several cases required further periods of IPPV (Cases 11, 19, 23, 28, 29, 31, 32, 34-40), all but 2 (Cases 23, 29) survived after a further period of distending pressure. Many such infants started spontaneous respirations while being ventilated and yet were unable to sustain an adequate $\mathrm{PaO}_{2}$ when breathing spontaneously at atmospheric pressure, but did so when distending pressure was applied. In some of those infants the arterial $\mathrm{Po}_{2}$ increased when CDP replaced IPPV at the same inspired oxygen concentration (Fig. 3). This was noted particularly in babies who were restless and had started to breathe out of phase with the ventilator. The improved oxygenation may be due to improved pulmonary perfusion since the pressure applied to the lung is lower with distending pressure than IPPV and also to the improved oxygenation which occurs when the sick infant lies quietly.

We found a moderately high incidence of pneumothoraces ( 7 out of $40,17.5 \%$ ), but it is within the range reported by other authors using distending pressure (Chernick, 1973). We have no data on the pressure in the head box applied to 2 of the infants, but with the other 5 the pressures were ranging from $8-10 \mathrm{~cm}$ and in 1 of these 5 the pneumothorax may have preceded the distending pressure. 5 of the 7 pneumothoraces and both cases with cysts alluded to above were in the head box at the time of diagnosis. There were no sudden rises in pressure and the pressures applied were no greater than those used by many other workers, though higher than those used by Dunn et al. (1973). The development of cysts during CDP has not been described before. In Case 32 we believe that the cyst was an example of the condition of intralymphatic air recently described by Stahlman, Cheatham, and Gray (1973) and believed by them to be due to rupture of alveoli into the lymphatics during high pressure IPPV such as used initially in this baby. In Case 5 the lesions may have been similar but they resolved spontaneously and the lung has remained normal since. Furthermore, this infant was not ventilated and the maximum distending pressure used was $8 \mathrm{~cm} \mathrm{H}_{2} \mathrm{O}$. We do not think that the cysts were the result of infection
(Avery, 1968; Kuhn and Lee, 1973), though Case 32 did grow Staphylococcus albus on one occasion from an endotracheal tube culture.

Vert, André, and Sibout (1973) reported the occurrence of intraventricular haemorrhage in association with distending pressure and related this to the increased intracranial vascular pressure when distending pressure is applied by a system which involves a tightly fitting neck seal. 3 babies in this series had proven intraventricular haemorrhages (Cases 11, 27, 39). 2 others probably occurred (Cases 25, 26), but permission for necropsy was refused. In the 3 confirmed cases 2 received distending pressure by endotracheal tube only (Cases 27, 39) and the third case (Case 11) developed signs and symptoms of intraventricular haemorrhage after recovering from RDS. After prolonged distending pressure and IPPV (Table IV) he survived but was noted to be hydrocephalic and died aged 6 weeks after an operation to insert a Pudenz valve. Necropsy showed hydrocephalus secondary to obstruction of the ventricular foramina by an old intraventricular haemorrhage. Even if Cases 25 and 26 did develop intraventricular haemorrhages, we would not regard an incidence of 5 intraventricular haemorrhages in 40 severe cases of RDS as excessive, and would not suggest any causal relation between distending pressure with or without neck constriction and IVH.

Cases 11 and 40 (Table IV) have been described in detail elsewhere (Roberton, 1974). Both had severe pulmonary oedema with heart failure due to a widely persistent ductus arteriosus. The use of distending pressure in this situation proved most satisfactory where pulmonary oedema could not be controlled pharmacologically. There are obvious disadvantages to all the methods of applying CDP. We do not feel safe in continuing oral feeds when applying CDP by head box as access to the upper airway is restricted should the child regurgitate. The poor access is also a disadvantage should apnoea occur and intubation be required. However, the trunk is easily accessible for clinical examination and $x$-rays. The problems are reversed with the negative pressure box, in that the access to the upper airway is good and feeding is possible, but clinical and radiological examination of the chest and abdomen is impossible without discontinuing the negative pressure. We have also had some difficulties in maintaining body temperature in the negative pressure box. Both box methods have the additional problem of maintaining an adequate neck seal without excoriating the baby's skin. We have minimized this by using a protective collar of gamgee wrapped in tube-gauze placed around the 
infant's neck underneath the iris diaphragm of the apparatus.

Using the endotracheal tube to administer the distending pressure avoids all the problems of the neck seal but substitutes the manifold problems of endotracheal tubes-obstruction, infection, and laryngeal injury. We had to change the tubes on average every 40 hours in our cases, and frequently this was required because of deterioration in the infant's condition when the tube became dislodged or obstructed. Furthermore, significant pathogens were grown from the airways of 9 of the infants and in several cases (e.g. Case 22) there were difficulties on extubation due to retained secretions and laryngeal oedema.

A trial of distending pressure administered by face mask, endotracheal tube, or CNP to matched groups of infants with RDS (Olinsky, MacMurray, and Swyer, 1973) showed no difference in outcome between the groups. However, the babies receiving treatment via an endotracheal tube received distending pressure for longer than the other groups. A similar comparison is not possible in our series since in only two cases (Cases 2, 15) was endotracheal intubation for the purpose of administering CDP used from the start. In our opinion endotracheal tubes should be used when other alternatives fail or when long-term distending pressure is required as with the 2 babies in Table IV.

The ability to feed such babies over the weeks, while the airway was protected by the endotracheal tube, counter-balanced the other disadvantages of the tube. The use of nasal catheters to administer distending pressure (Novogroder et al., 1973; Kattwinkel et al., 1973) seems to us a logical alternative of which we have had no personal experience.

There are no published data on the optimum indications for starting distending pressure. We have not found the hyperoxia text useful in forecasting either the need for CDP or the ultimate outcome of the disease. While there is no doubt that CDP increases survival (Fanaroff et al., 1973; Rhodes and Hall, 1973), the technique places an extra load on the nursing and medical staff and we would not be in favour of its use liberally if it distracted facilities away from the more critically ill infants in a busy nursery. Moreover, CDP does carry a definite increased risk of pneumothorax$17.5 \%$ in this series and up to $24 \%$ in other series (Chernick, 1973), a complication of RDS which in our unit doubles the mortality rate. For these reasons we feel the technique should only be used where adequate facilities for monitoring and intensive care are available.
We wish to thank Professor J. P. M. Tizard and Drs. H. L. Ellis, B. D. Bower, and D. Pickering for allowing us to study babies under their care; and Miss P. Townshend and the nursing staff of the Special Care Baby Unit who looked after the babies.

\section{REFERENCES}

Avery, M. E. (1968). The Lung and its Disorders in the Newborn Infant, 2nd ed., p. 102 . Saunders, Philadelphia, London, and Toronto.

Boston, R. W., Geller, F., and Smith, C. A. (1966). Arterial blood gas tensions and acid-base balance in the management of the respiratory distress syndrome. Fournal of Pediatrics, 68, 74.

Chernick, V. (1973). Treatment of hyaline-membrane disease. New England fournal of Medicine, 289, 302.

Chernick, V., and Vidyasagar, D. (1972). Continuous negative chest wall pressure in hyaline membrane disease. Pediatrics, 49, 753.

Cumarasamy, N., Nüssli, R., Vischer, D., Dangel, P. H., and Duc, G. V. (1973). Artificial ventilation in hyaline membrane disease: the use of positive end-expiratory pressure and continuous positive airway pressure. Pediatrics, 51, 629.

Davies, P. A., Robinson, R. J., Scopes, J. W., Tizard, J. P. M., and Wigglesworth, J. S. (1972). Medical Care of Newborn Babies. Heinemann, London.

Dunn, P. M., Speidel, B. D., and Storrs, C. N. (1973). In defence of the Gregory Box (C.P.A.P.). Lancet, $2,853$.

Etches, P. C., Houghton, C., and Moore, W. J. (1973). C.P.A.P. via endotracheal tube. Lancet, 1, 271.

Fanaroff, A. A., Cha, C. C., Sosa, R., Crumrine, R. S., and Klaus, M. H. (1973). Controlled trial of continuous negative external pressure in the treatment of severe respiratory distress syndrome. Fournal of Pediatrics, 82, 921.

Gregory, G. A., Kitterman, J. A., Phibbs, R. H., Tooley, W. H., and Hamilton, W. K. (1971). Treatment of idiopathic respiratorydistress syndrome with continuous positive airways pressure. New England Fournal of Medicine, 284, 1333.

Harrison, V. C., Heese, H. de V., and Klein M. (1968). The significance of grunting in hyaline membrane disease. Pediatrics, 41, 549.

Hatch, D. J., Cogswell, J. J., Taylor, B. W., Battersby, E. F., Glover, W. J., and Kerr, A. A. (1973). Continuous positive-airway pressure after open-heart operations in infancy. Lancet, 2, 469.

Kattwinkel, J., Fleming, D., Cha, C. C., Fanaroff, A. A., and Klaus, M. H. (1973). A device for administration of continuous positive airway pressure by the nasal route. Pediatrics, 52, 131.

Kuhn, J. P., and Lee, S. B. (1973). Pneumatoceles associated with Escherichia coli pneumonias in the newborn. Pediatrics, 51, 1008.

Novogroder, M., MacKuanying, N., Eidelman, A. I., and Gartner, L. M. (1973). Nasopharyngeal ventilation in respiratory distress syndrome. Fournal of Pediatrics, 82, 1059.

Olinsky, A., MacMurray, S. B., and Swyer, P. R. (1973). Continuous pressure breathing in RDS, comparative trial of 3 methods. Paper presented to International Conference on Intensive Care of the Newborn, Banff, Canada.

Rhodes, P. G., and Hall, R. T. (1973). Continuous positive airway pressure delivered by face mask in infants with the idiopathic respiratory distress syndrome. A controlled study. Pediatrics, 52, 1 .

Roberton, N. R. C. (1974). Prolonged continuous positive airways pressure for pulmonary oedema due to persistent ductus arteriosus in the newborn. Archives of Disease in Childhood, 49, 585.

Roberton, N. R. C., Gupta, J. M., Dahlenburg, G. W., and Tizard, J. P. M. (1968). Oxygen therapy in the newborn. Lancet, 1, 1323.

Stahlman, M., Cheatham, W., and Gray, M. E. (1973). Interstitial emphysema and chronic lung disease in post-ventilator hyaline membrane disease. Paper presented to International Conference on Intensive Care of the Newborn, Banff, Canada.

Vert, P., André, M., and Sibout, M. (1973). Continuous positive airway pressure and hydrocephalus. Lancet, 2, 319.

Correspondence to Dr. J. D. Baum, Department of Paediatrics, John Radcliffe Hospital, Headington, Oxford OX3 9DU. 